central seeing areas were circular in shape and not elliptical and there were no islands of preserved vision in the periphery of the fields as reported by de Schweinitz ${ }^{3}$.

Before concluding we would like to express our opinion that since malaria is so common in the tropics and quinine is so freely used, some of the cases of optic atrophy in which no definite cause can be found might be due to toxicity of quinine.

\title{
REFERENCES
}

1. Ball.-Modern Ophthalmology, p. 889.

2. Elliot.-Tropical Ophthalmology, p. 466.

3. de Schweinitz.-Concerning Quinine Blindness with the Report of a Case. Arch. of Ophthal., Vol. XXXIX, p. 101, 1910.

\section{A CASE OF QUININE AMBLYOPIA WITH A CENTRAL COLOUR SCOTOMA OF ONE EYE AND TOTAL BLINDNESS OF THE OTHER}

\author{
BY \\ Lt.-Col. J. N. Duggan, O.B.E., D.O.(Oxon.), F.C.P.S. \\ AND \\ B. P. Nanavati, D.O.M.S., M.R.C.S.(Eng.), L.R.C.P.(Lond.)
}

SINCE total blindness of one eye and a central colour scotoma of the seeing eye are unusual features in quinine amblyopia we consider such a case worthy of publication. We had come across two cases of quinine amblyopia with unusual fundal appearance and a paper on the subject was read at the 13th International Ophthalmological Congress, but in these interesting cases the above mentioned features did not exist, hence we take the opportunity of adding this one to those two, an abstract of which will be found published in the Transactions of the 13th Ophthalmological Congress. In case the Transactions are not available for reference we mention here that in the early stage, i.e., during the first three days, the disc and blood vessels remained normal and then the fundi showed the classical picture of quinine amblyopia. In both the paradox of quinine amaurosis, i.e., improvement of vision with contraction of blood vessels and appearance of white lines along them was noted. In one case both the fundi showed small yellowish white glistening dots arranged irregularly round the maculae. 
Five years ago, the patient, a lady aged 25 years, took about five ounces of quinine all at once for reasons best known to her, for no proper cause for taking it was given. Immediately after taking it she had all the signs and symptoms of cinchonism together with collapse. On recovery from unconsciousness the next morning, she found herself totally blind in both eyes. Her parents took her to Miraj for treatment and in about four months she recovered her sight which was equally good in both eyes. On her return to

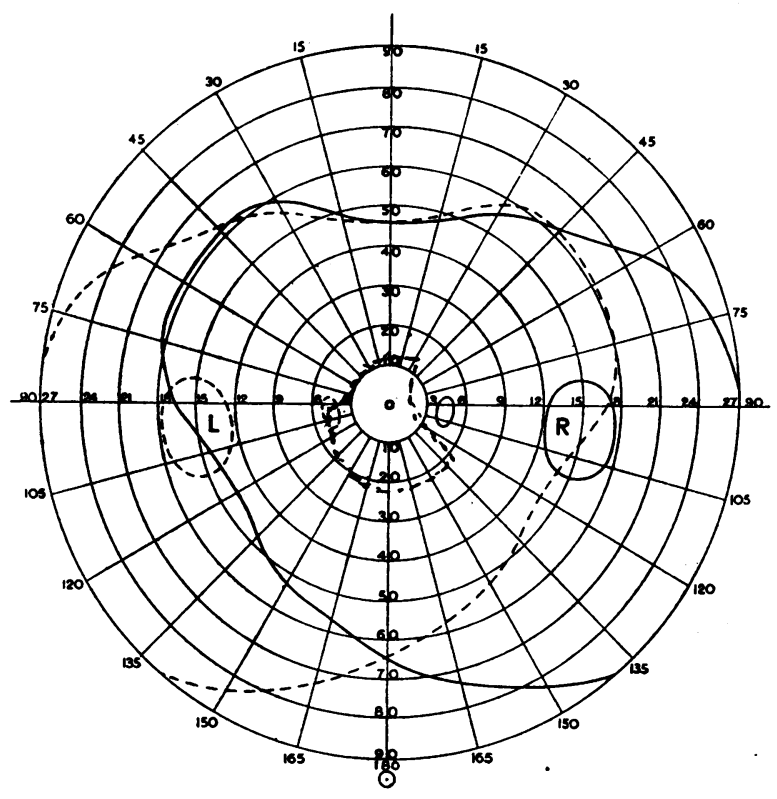

Bombay she found that her right eye had gone suddenly blind without any cause and ever since it has remained so. On examination the pupils, though of usual size, were sluggish in reaction. Vision of right eye was reduced to hand movements and that of left eye finger counting at four feet and improved to $6 / 12$ with -4.5 D. sph. with -1.0 D. cyl. $70^{\circ}$. She read J.2 with $-2.0 \mathrm{D}$. sph. -1.0 D. cyl. $70^{\circ}$ and even preferred to do her work without any glasses. As there was a central colour scotoma, she found it difficult to pick up the first word of a sentence.

Field of vision of left eye was irregularly contracted within $20^{\circ}$ circle, on the nasal side its limits almost approaching the fixation point (see chart attached). On examining for central colour scotoma it was found that she could easily make out all the colours of large discs except that of the green, while testing with tiny ones 
a definite scotoma for green was made out though at times she was not certain even about the red colour.

There was optic atrophy of both discs. Blood vessels were reduced to mere red streaks with white lines along them and beyond the border of the discs they were mere thin white lines. Though the right eye was blind the fundus appearances.were quite similar.

Comments:-Generally the prognosis in quinine amblyopia is good, but in this case though the pallor of both discs is equally marked one eye is blind and it is difficult to give any definite cause for it. However, five years after the onset the left eye has still good vision though her field of vision has remained very much contracted. Another point of interest is the central colour scotoma as a result of which she is particularly embarrassed while doing her near work. This rare phenomenon was reported by Galezowski, de Wecker, Jodko, Bietti and Edgar Smith and this was found mentioned in Ball's Modern Ophthalmology on page 890. The presence of a central colour scotoma seems to support one of the theories that quinine-directly attacks ganglion cells of the retina and this leads to ascending degeneration of the nerve fibres of the optic nerve. But it seems quite probable that the degeneration of nerve fibres is primarily due to lack of circulation.

\title{
TREPHINING IN THE TREATMENT OF CONGENITAL GLAUCOMA
}

BY

\author{
Lt.-Col. R. E. Wright, C.I.E., M.D., I.M.S. \\ AND \\ K. Koman Nayar, L.R.C.P. \& S., D.O.M.S. \\ GOVERNMENT OPHTHALMIC HOSPITAL, MADRAS, INDIA
}

THIs condition is not uncommonly met with here in all its phases; about three or four cases a year are seen by the writers. In common with other observers, we have sometimes found its treatment by trephining very disappointing, but not by any means always. We have noticed that some eminent ophthalmologists are so unfavourably impressed with decompression operations on the anterior segment that they consider repeated posterior sclerotomy the operation of choice in this affection. Posterior sclerotomy, as an operative treatment in any condition of the eye, has always seemed to us a remedy to be avoided if some less drastic procedure 